Supporting Information

\title{
Preferential Binding of Thioflavin T to AT-rich DNA: White Light Emission through Intramolecular Förster Resonance Energy Transfer
}

Srikrishna Pramanik,* Atanu Nandy, Subhajit Chakraborty, Ushasi Pramanik, Somen Nandi, and Saptarshi Mukherjee*

Department of Chemistry, Indian Institute of Science Education and Research Bhopal, Bhopal Bypass Road, Bhopal 462066, Madhya Pradesh, India

E-mail: skrishna@iiserb.ac.in

saptarshi@iiserb.ac.in 
Page No.

1. Experimental Section $\quad$ S3

2. Figure $\mathrm{S} 1 \quad$ S5

3. Figure $\mathrm{S} 2$

4. Figure S3 S5

5. Table S2 S6

6. Figure $\mathrm{S} 4 \quad$ S6

7. Figure S5 S6

8. Figure $\mathrm{S6} \quad \mathrm{S7}$

9. Table S3 S7

$\begin{array}{ll}\text { 10. Figure } \mathrm{S} 7 & \mathrm{~S} 7\end{array}$

11. Figure $\mathrm{S} 8 \quad$ S8

12. Figure $\mathrm{S} 9 \quad$ S8

13. Figure S10 S9

14. Table S4 S9

15. Figure S11 S10

16. Figure S12

17. Figure S13 S11

18. Figure S14 S11

19. Table S5 $\quad \mathrm{S} 12$

20. Table S6 $\quad \mathrm{S} 12$

21. Table S7 $\quad \mathrm{S} 12$

22. Figure S15 $\quad$ S13

23. Figure S16 S13

24. Table S8

25. Table S9 $\quad \mathrm{S} 14$

26. Table S10 $\quad$ S14 


\section{EXPERIMENTAL SECTION}

Materials: Thioflavin T, customized DNA (HPLC grade, Table 1) and Ethidium Bromide (EtBr) were all purchased from Sigma-Aldrich Corp. (St. Louis, MO, USA), and were utilized as received. DNA stock solutions of were prepared in $10 \mathrm{mM}$ phosphate buffer of $\mathrm{pH} \sim 7.4$, having $50 \mathrm{mM} \mathrm{NaCl}$. DNA solutions were heated at $90^{\circ} \mathrm{C}$ and then gradually cooled to $25^{\circ} \mathrm{C}$ and stored at $4^{\circ} \mathrm{C}$ for 24 hour before the interaction studies. Buffer solution was prepared using triply distilled Milli pore water.

Table S1. Summary of Different DNA

\begin{tabular}{|c|c|c|c|}
\hline DNA Sequences & AT & $\mathrm{GC}$ & Abbreviation \\
\hline$-3^{\prime}$ & $\begin{array}{c}\text { Content } \\
(\%)\end{array}$ & $\begin{array}{c}\text { Content } \\
(\%)\end{array}$ & \\
\hline ATATATATATATATATATAT & 100 & 0 & AT DNA/(AT) $)_{100}$ \\
\hline ATATATATATATATATATGC & 90 & 10 & $(\mathrm{AT})_{90}$ \\
\hline ATATATATATATATGCGCGC & 70 & 30 & $(\mathrm{AT})_{70}$ \\
\hline ATATATATATGCGCGCGCGC & 50 & 50 & $\mathrm{ATGC} \mathrm{DNA} /(\mathrm{AT})_{50}$ \\
\hline ATATATGCGCGCGCGCGCGC & 30 & 70 & $(\mathrm{AT})_{30}$ \\
\hline GCGCGCGCGCGCGCGCGCGC & 0 & 100 & $\mathrm{GC}$ DNA/(AT) $)_{0}$ \\
\hline
\end{tabular}

\section{Instrumentation:}

UV-Vis absorbance titration: Absorbance spectra of ThT in the presence of different concentrations of dsDNA were recorded in a Cary-100 UV-Vis spectrophotometer (200-800 nm).

Fluorescence titration. Steady state fluorescence data were collected in phosphate buffer solutions using a Horiba Jobin-Yvon, Fluorolog 3-111 by keeping both the excitation and emission slits at $1 \mathrm{~nm}$. Measurements were taken after 1 minute of each sequential addition. We calculated the binding constant values by using the modified Benesi-Hildebrand equation.

$\frac{1}{\Delta F}=\frac{1}{\Delta F_{\max }}+\frac{1}{K_{B}\left(\Delta F_{\max }\right)} \times \frac{1}{[D N A]}$

Here, $\Delta F=$ (Fluorescence intensity of free ThT-DNA bound ThT), $\Delta F_{\max }$ is the difference in the fluorescence intensity at the highest DNA concentration. The apparent binding constant, $K_{\mathrm{B}}$ is determined from intercept to the slope ratio of the linear plot.

The relative fluorescence quantum yield of ThT-DNA systems were estimated with respect to Coumarin 153 (having quantum yield 0.53 in ethanol) as standard by using following equation. 
$(Q Y)_{T h T-D N A}=(Q Y)_{\text {standard }}\left(\frac{I_{T h T-D N A}}{I_{\text {standard }}}\right)\left(\frac{A_{\text {standard }}}{A_{\text {ThT-DNA }}}\right)\left(\frac{\eta_{T h T-D N A}}{\eta_{\text {standard }}}\right)^{2}$

Here, $I$ is the integrated peak intensity of the fluorescence curve, $A$ represents the absorbance at $420 \mathrm{~nm}$ and $n$ is the refractive index of solvent (1.33 for water and 1.36 for ethanol). Optical density was kept under 0.05 at 420 nm.

Lifetime measurements. The fluorescence lifetime of free ThT and DNA bound ThT were recorded at $405 \mathrm{~nm}$ excitation wavelength using an IBH-NanoLED source N-405 (Instrument Response Function, IRF was found to be $\sim 100 \mathrm{ps}$ ) and at $486 \mathrm{~nm}$ emission wavelength. The details of the instrumentation are mentioned elsewhere. ${ }^{1}$

Association kinetics analyses from time trace. Fluctuations in the fluorescence intensity during binding and unbinding processes were measured using confocal setup (PicoQuant, MicroTime 200) with an inverted optical microscope (Olympus IX-71), described in detail elsewhere. ${ }^{2,3}$ During this experiment, the ThT and ThT-DNA solutions were excited at $\lambda_{\mathrm{ex}}=405 \mathrm{~nm}$ and the data were processed by Sympho Time software provided by PicoQuant. Binding of different dsDNA to ThT augments the fluorescence intensity of ThT. Each period of association and dissociation were considered as an off-time $\left(\tau_{\text {off }}\right)$ and on-time $\left(\tau_{\mathrm{on}}\right)$, respectively. Individual on and off-time cumulative histograms were fitted using a single-exponential function. ${ }^{4}$ Association $\left(k_{\text {ass }}\right)$ and dissociation $\left(k_{\text {diss }}\right)$ rate constants were estimated from the inverse of the time component deduced from the offtime and on-time histogram, respectively and concentration of ThT.

Molecular Docking. Docking study was performed using AutoDock 4.2.2 software., ${ }^{5,6}$ After optimizing the three dimensional geometry of ThT and EtBr from the calculation using Gaussian 09 software ${ }^{7}$ (DFT/b3lyp/6$31 \mathrm{G}(\mathrm{d}, \mathrm{p}))$, the optimized structure was taken for docking. The DNA sequence had been made in Avogadro Molecular Builder 1.2.0 $0^{8}$ to perform the docking. The parameters used for docking were selected as below: grid size along X-, Y- and Z- axes were 126, 70 and 66 respectively with grid spacing $0.647 \AA$ for the ATGC DNA, AT DNA and GC DNA. Grid size along X-, Y- and Z- axes were 126, 56 and 64 respectively with grid spacing $0.403 \AA$ for the AT rich region of the ATGC DNA and for the GC rich region the grid size along X-, Y- and Zaxes were 90, 72 and 126 respectively with grid spacing $0.375 \AA$ A. GA (Genetic Algorithm) population size was 150; maximum number of energy evaluations was 250000; GA crossover mode was two points. The minimum energy conformation (out of 50 different conformations) after a blind investigation was analyzed using PyMOL software. ${ }^{9}$ 

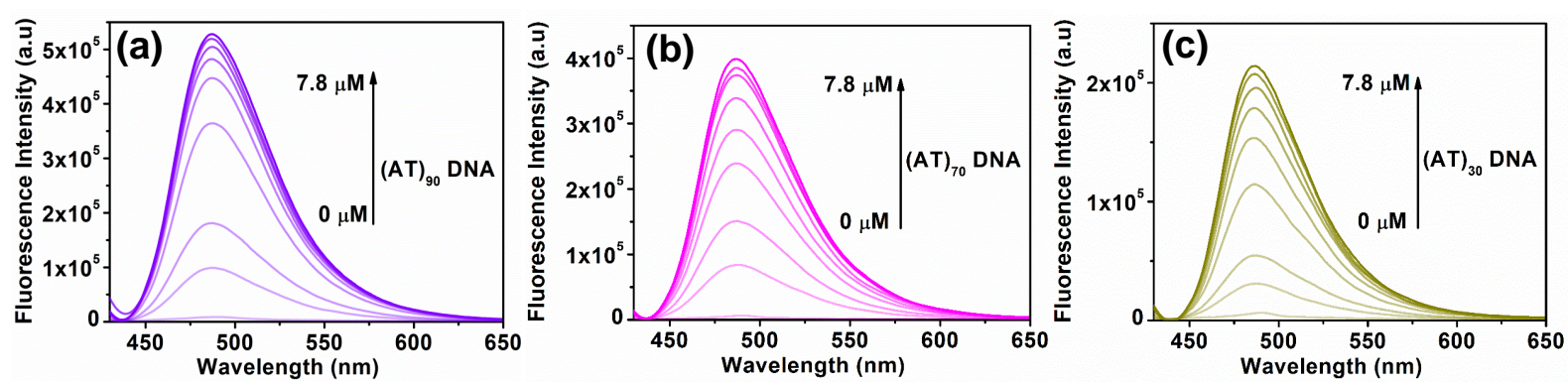

Figure S1. Fluorescence response of ThT in the presence of DNA having (a) $90 \%$ AT base pair, (b) $70 \%$ AT base pair and (c) $30 \%$ AT base pair.

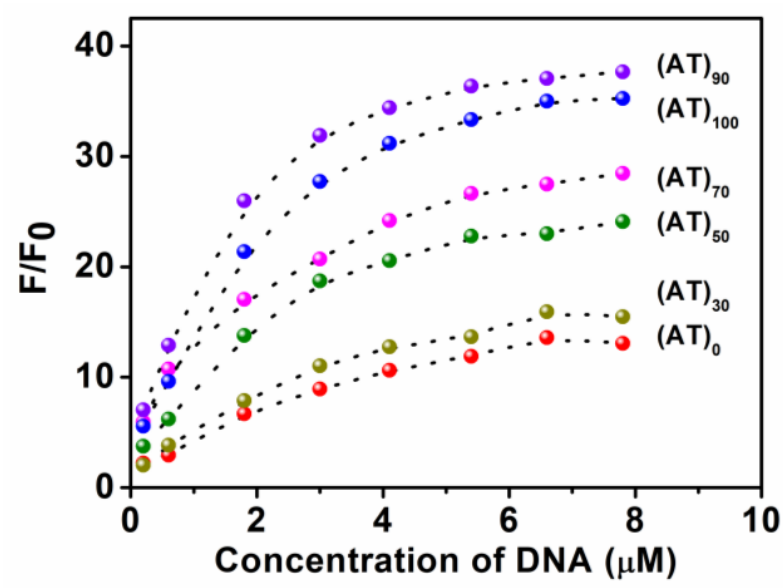

Figure S2. Relative changes in the fluorescence intensity of ThT with respect to different DNA concentrations having varied compositions. Here $F_{0}$ and $F$ are respectively, the fluorescence intensities of ThT in the absence and presence of the added DNA.
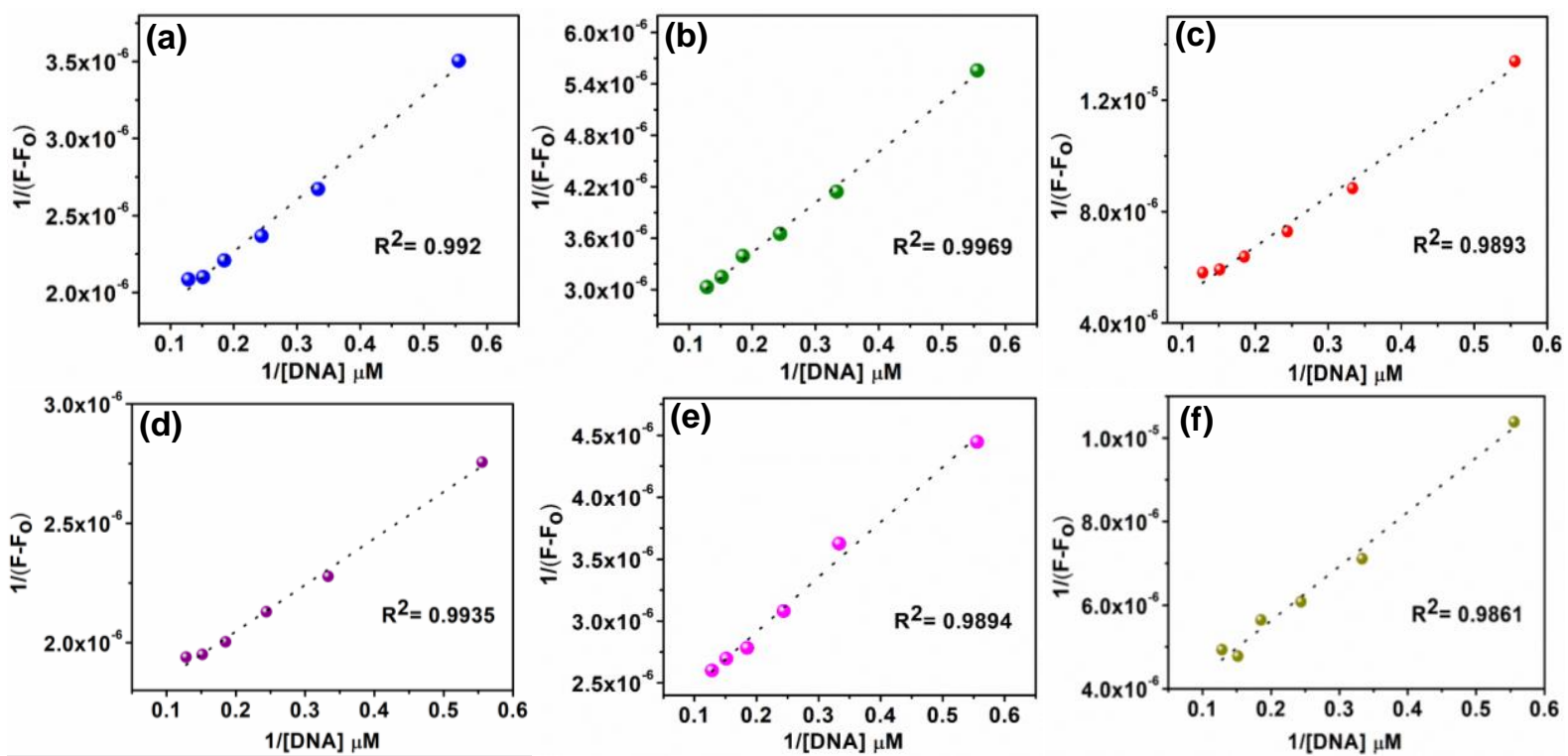

Figure S3. (a-f) Modified Benesi-Hildebrand plots of ThT- DNA systems. (a) ThT-AT DNA, (b) ThT-ATGC DNA, (c) ThT-GC DNA, (d) ThT-(AT) 90, (e) ThT-(AT) 70 and (f) ThT-(AT) ${ }_{30}$ DNA. 
Table S2. Apparent Binding Constant Values of all ThT-DNA systems

\begin{tabular}{|c|c|c|c|c|}
\hline DNA Sequences & \multirow{2}{*}{$\begin{array}{c}\mathrm{AT} \\
\text { Content } \\
(\%)\end{array}$} & \multirow{2}{*}{$\begin{array}{c}\mathrm{GC} \\
\text { Content } \\
(\%)\end{array}$} & \multirow[t]{2}{*}{ Abbreviation } & \multirow{2}{*}{$\begin{array}{l}\text { Binding Constant } \\
\left(\mathrm{M}^{-1}\right)\end{array}$} \\
\hline$-3^{\prime}$ & & & & \\
\hline ATATATATATATATATATAT & 100 & 0 & AT DNA/(AT) $)_{100}$ & $4.7 \pm 0.2 \times 10^{5}$ \\
\hline ATATATATATATATATATGC & 90 & 10 & $(\mathrm{AT})_{90}$ & $5.2 \pm 0.4 \times 10^{5}$ \\
\hline ATATATATATATATGCGCGC & 70 & 30 & $(\mathrm{AT})_{70}$ & $4.4 \pm 0.2 \times 10^{5}$ \\
\hline ATATATATATGCGCGCGCGC & 50 & 50 & ATGC DNA/(AT) $)_{50}$ & $3.8 \pm 0.2 \times 10^{5}$ \\
\hline ATATATGCGCGCGCGCGCGC & 30 & 70 & $(\mathrm{AT})_{30}$ & $2.3 \pm 0.3 \times 10^{5}$ \\
\hline GCGCGCGCGCGCGCGCGCGC & 0 & 100 & $\mathrm{GC}$ DNA/(AT) $)_{0}$ & $9.9 \pm 0.1 \times 10^{4}$ \\
\hline
\end{tabular}
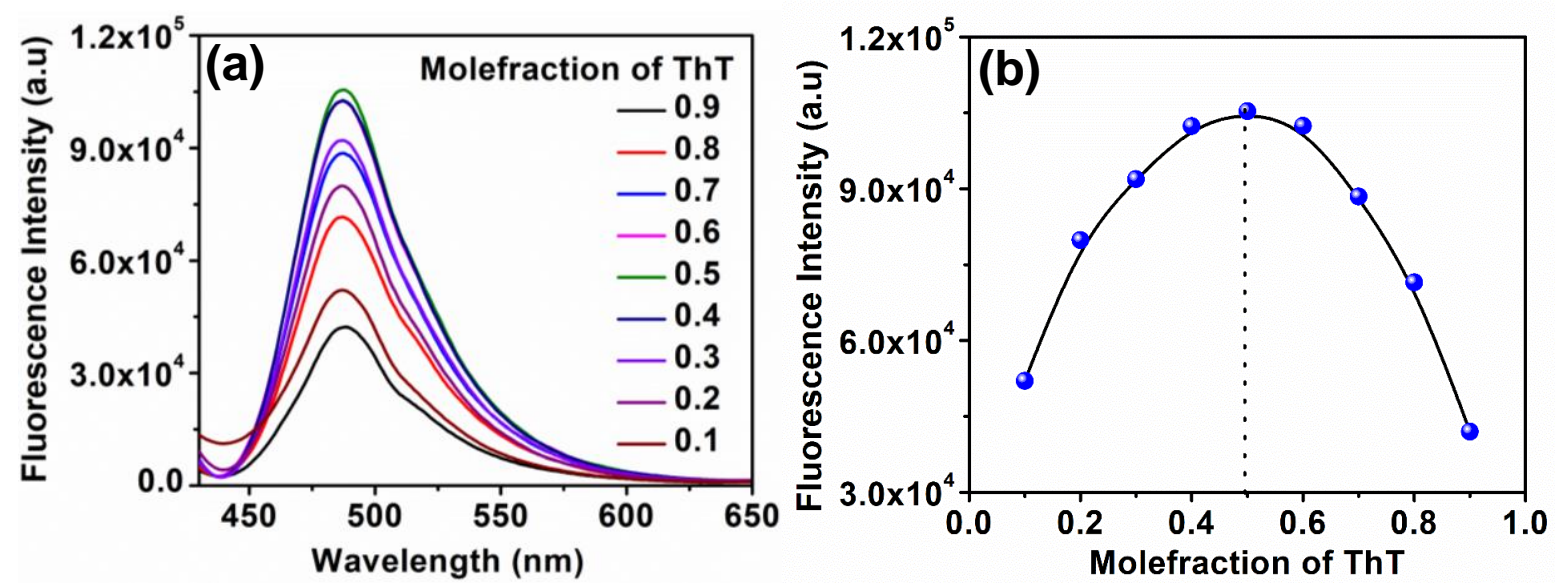

Figure S4. (a) Variation of fluorescence intensities of ThT in the presence of varying molefractions of ThT and AT DNA and (b) Jobs Plot of ThT and AT DNA corresponding to the 1:1 binding between ThT-AT DNA.
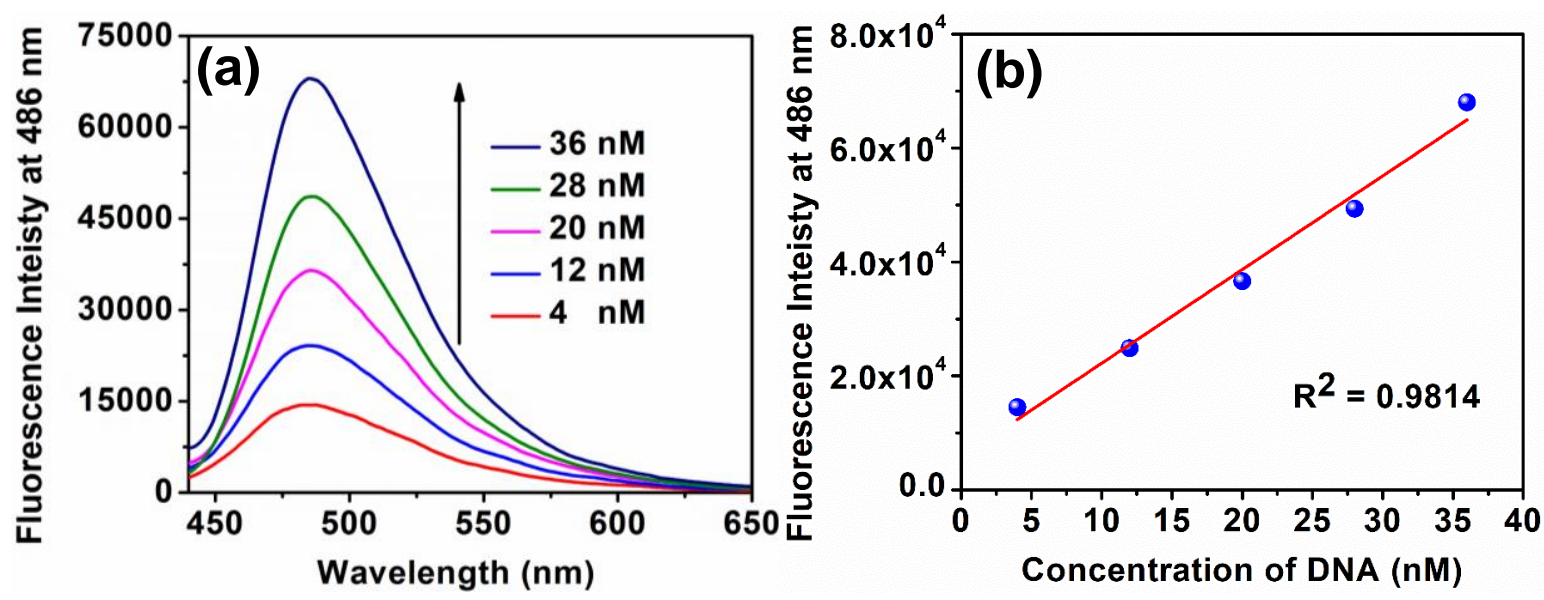

Figure S5. (a) Fluorescence spectra of ThT in the presence of different lower concentrations of AT DNA as marked in the figure and (b) linear response of the fluorescence signals with respect to DNA concentration. 


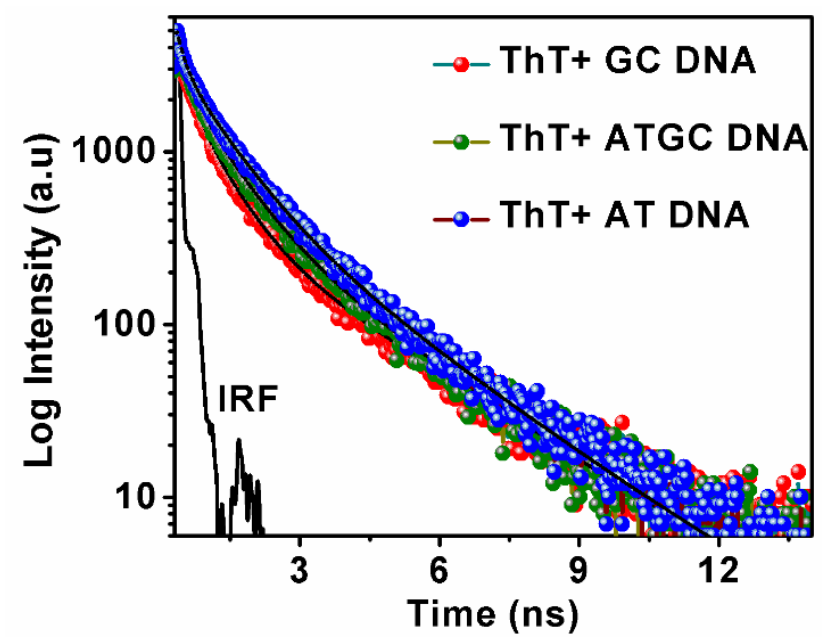

Figure S6. Fluorescence lifetime decay transients of ThT in the presence of different dsDNA.

Table S3. Excited State Fluorescence Lifetime Data of ThT in the Presence of Different DNA

\begin{tabular}{ccccc}
\hline System & $\tau_{1}\left(\alpha_{1}\right)$ & $\tau_{2}\left(\alpha_{2}\right)$ & $\tau_{3}\left(\alpha_{3}\right)$ & $\chi^{2}$ \\
\hline ThT + AT DNA & $1.01 \mathrm{~ns}(47.10)$ & $0.35 \mathrm{~ns}(19.83)$ & $2.22 \mathrm{~ns}(33.07)$ & 1.36 \\
ThT + ATGC DNA & $1.11 \mathrm{~ns}(45.20)$ & $0.35 \mathrm{~ns}(28.80)$ & $2.52 \mathrm{~ns}(26.00)$ & 1.38 \\
ThT + GC DNA & $0.99 \mathrm{~ns}(45.72)$ & $0.30 \mathrm{~ns}(31.61)$ & $3.43 \mathrm{~ns}(22.67)$ & 1.17 \\
\hline
\end{tabular}
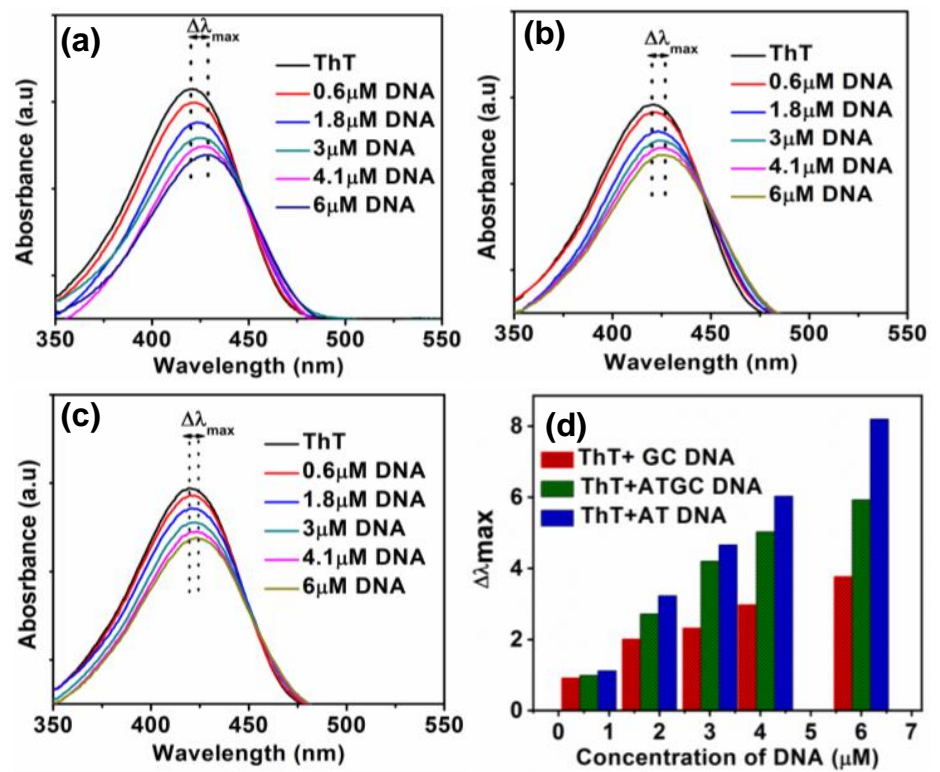

Figure S7. (a), (b) and (c) represent the absorbance spectra of ThT in the presence of AT, ATGC and GC DNA, respectively (d) represents the changes in the absorbance maxima $\left(\Delta \lambda_{\max }\right)$ of ThT after interacting with dsDNA. 


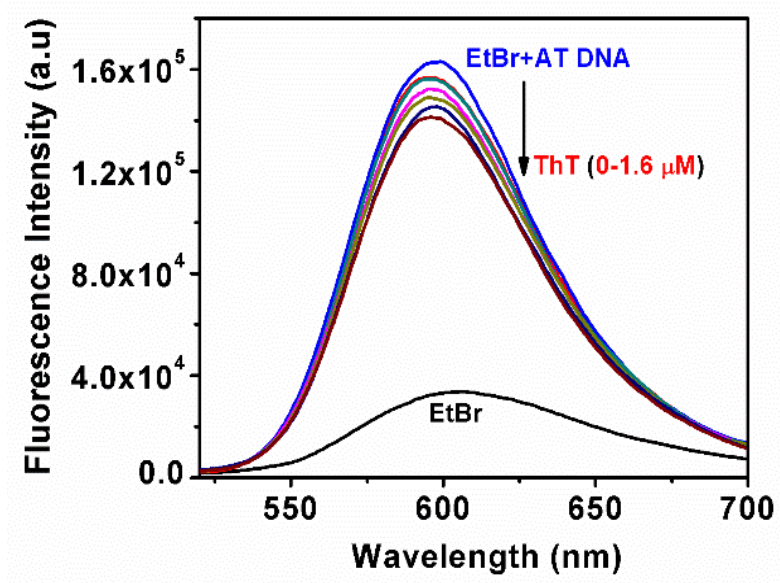

Figure S8. Fluorescence spectra of AT DNA bound EtBr in the presence of increasing concentrations of ThT.
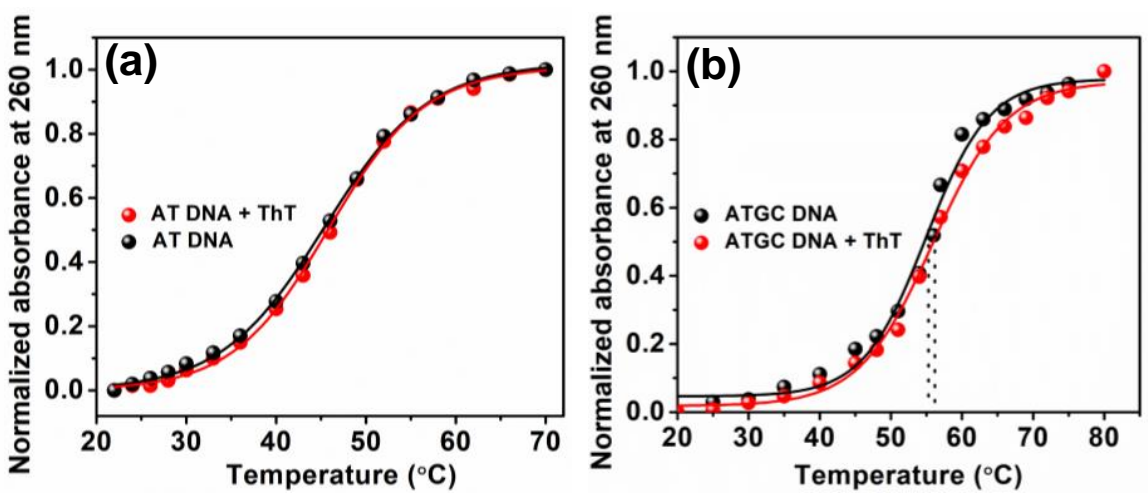

Figure S9: Melting temperature profiles of (a) AT DNA and (b) ATGC DNA in the absence and presence of ThT as marked in the figure. 

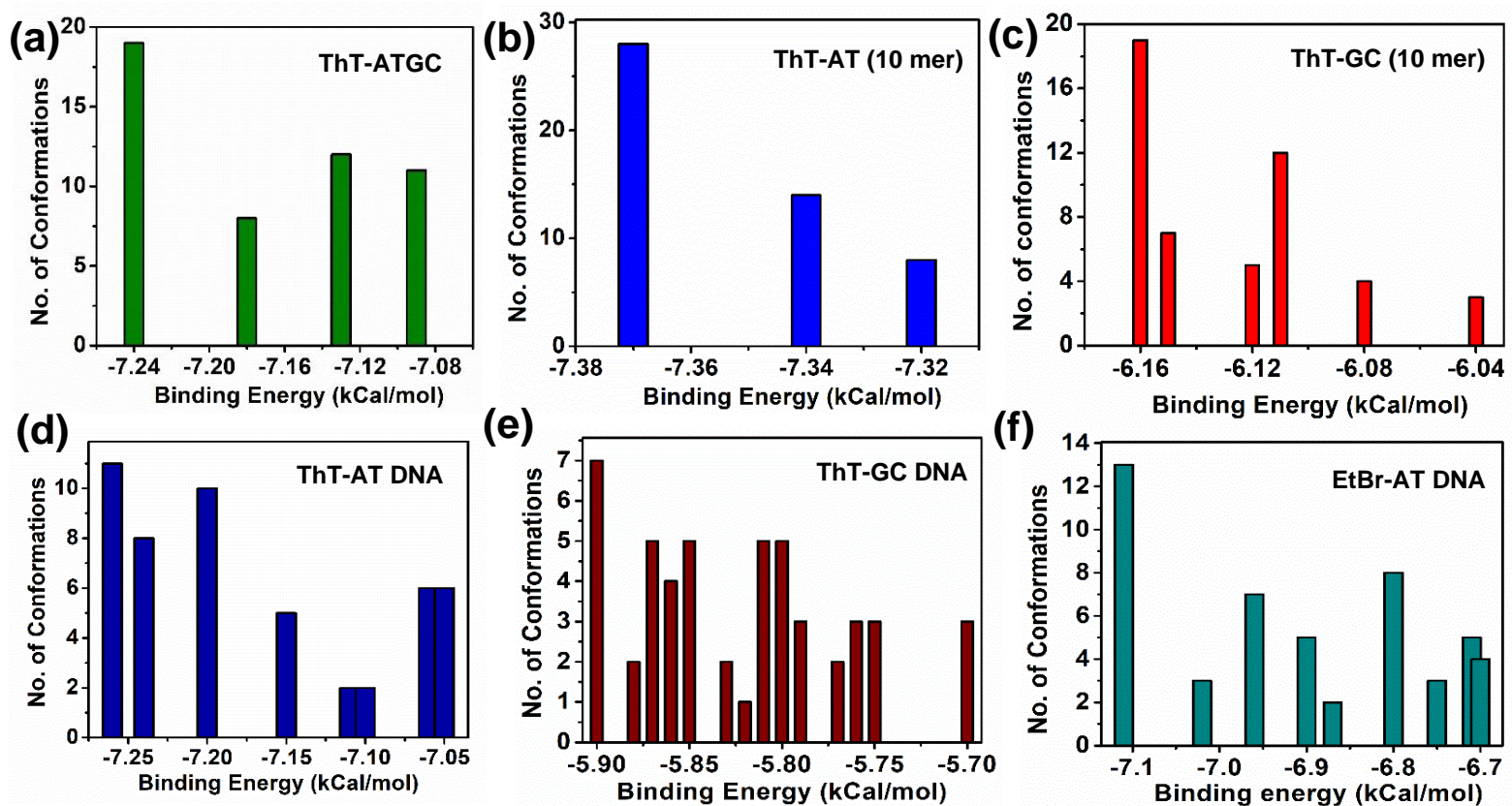

(e)
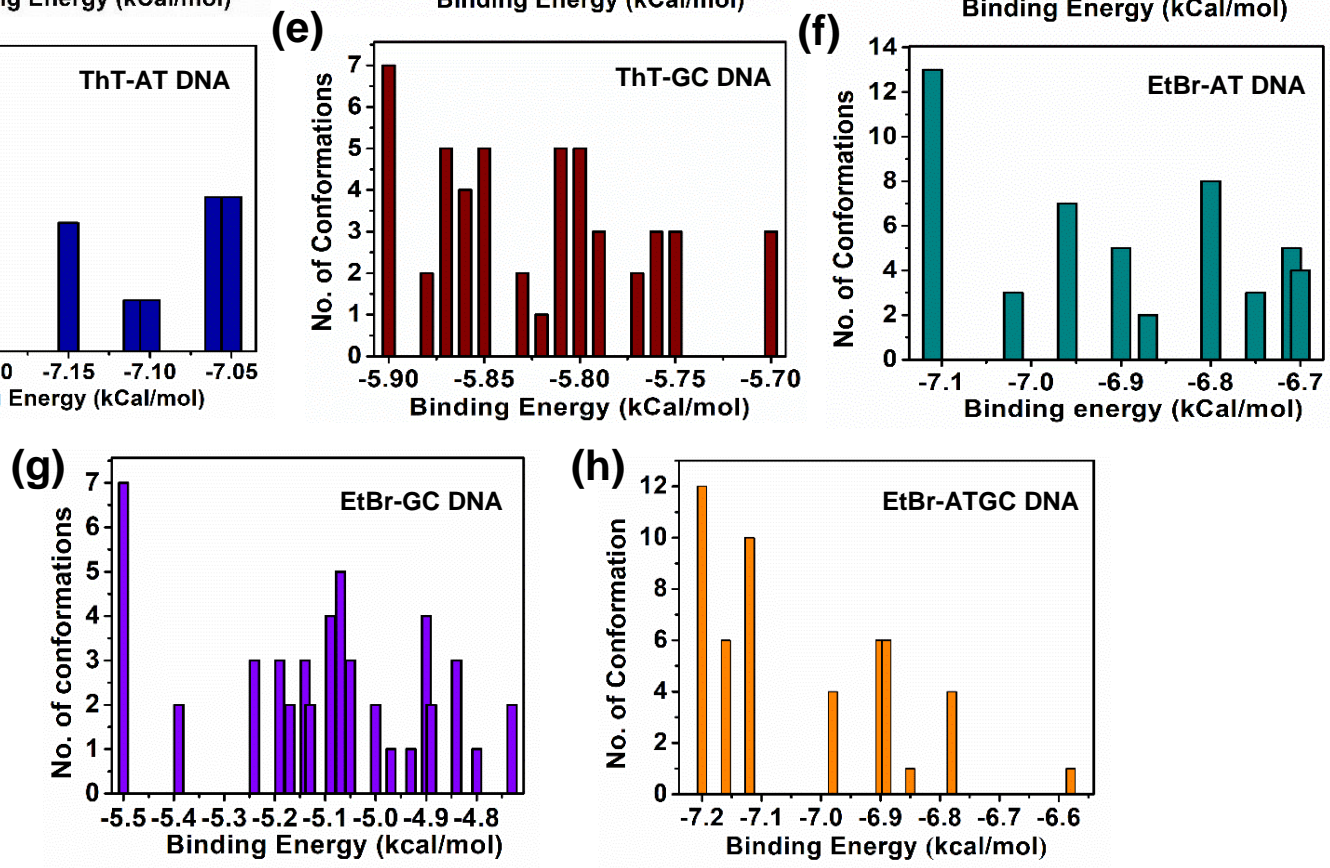

Figure S10. Cluster histograms of the various DNA and ThT/EtBr Docked conformation as marked in the figure.

Table S4. Molecular Docking Results of the Interaction Between ThT/EtBr with Different DNA

\begin{tabular}{|ccccc|}
\hline DNA & \multicolumn{2}{c}{ Energy $\left(\mathrm{kJ} \mathrm{mol}^{-1}\right)$} & \multicolumn{2}{c|}{$K\left(\mathrm{M}^{-1}\right)$} \\
\cline { 2 - 5 } & ThT & $\mathrm{EtBr}$ & ThT & EtBr \\
\hline 5'-ATATATATATGCGCGCGCGC-3' & -31.16 & -30.24 & $2.8 \times 10^{5}$ & $1.99 \times 10^{5}$ \\
(ATGC DNA) & & & & \\
Only AT region of ATGC DNA & -30.95 & -31.58 & $2.65 \times 10^{5}$ & $3.42 \times 10^{5}$ \\
Only GC region of ATGC DNA & -25.66 & -26.08 & $3.13 \times 10^{4}$ & $3.7 \times 10^{4}$ \\
5'-ATATATATATATATATATAT-3' & -30.49 & -29.86 & $2.19 \times 10^{5}$ & $1.72 \times 10^{5}$ \\
(AT DNA) & & & & \\
5'-GCGCGCGCGCGCGCGCGCGC-3' & -24.78 & -23.1 & $2.2 \times 10^{4}$ & $1.12 \times 10^{4}$ \\
(GC DNA) & & & & \\
\hline
\end{tabular}



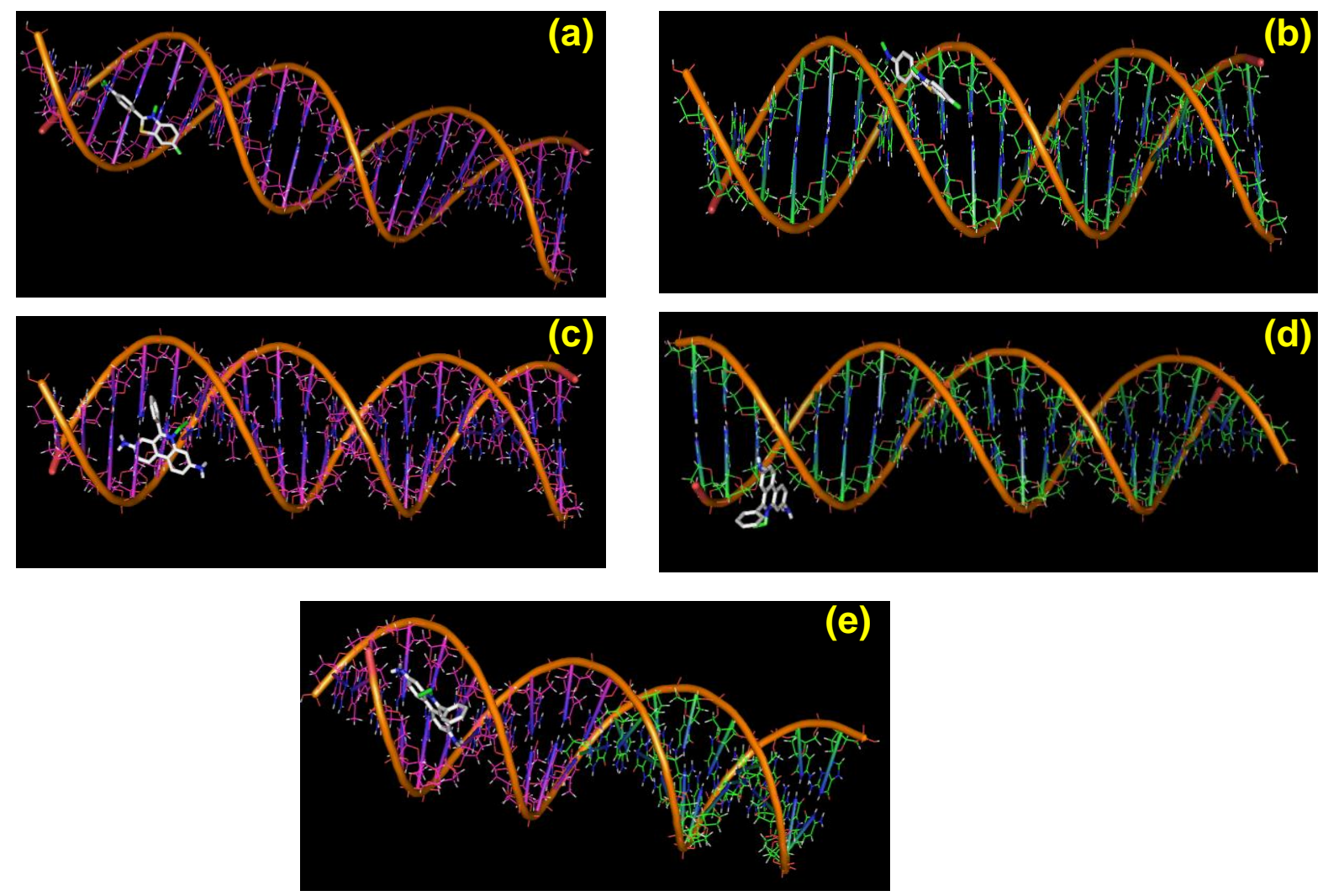

Figure S11. Molecular docking study of (a) ThT in the 20 mer AT DNA, (b) ThT in the 20 mer GC DNA, (c) EtBr in the 20 mer AT DNA, (d) EtBr in the 20 mer GC DNA and (e) EtBr in the 20 mer ATGC DNA at the lowest energy structures.

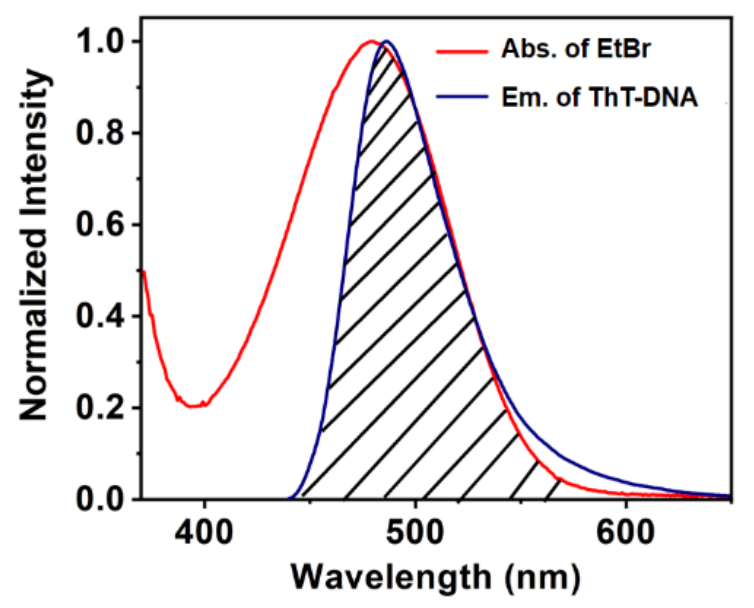

Figure S12. Spectral overlap between absorbance spectrum of EtBr and fluorescence spectrum of AT DNA bound ThT. This significant spectral overlap makes them an excellent FRET pair. 


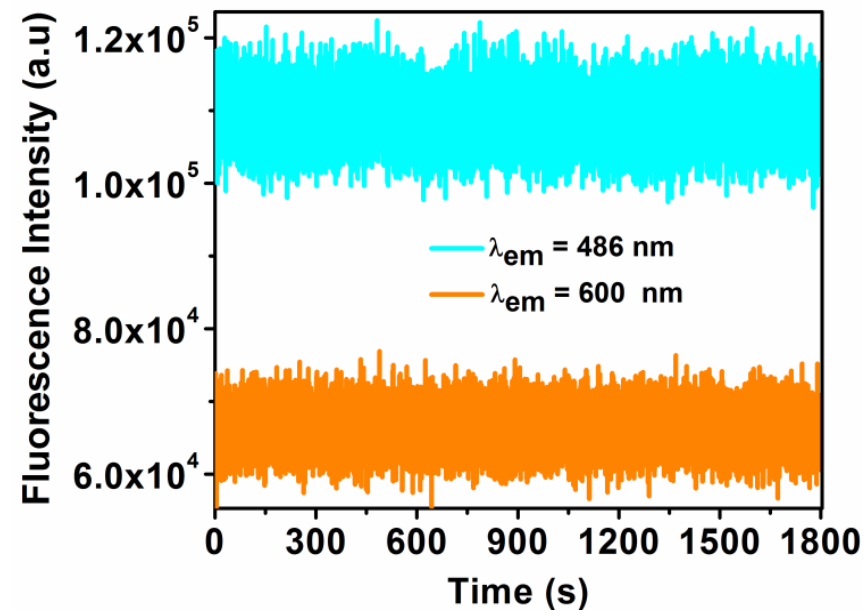

Figure S13. Fluorescence trajectories displaying the photostable nature of the ThT-DNA (at $486 \mathrm{~nm})$ and EtBr (600 $\mathrm{nm})$ mixed system as a function of time.

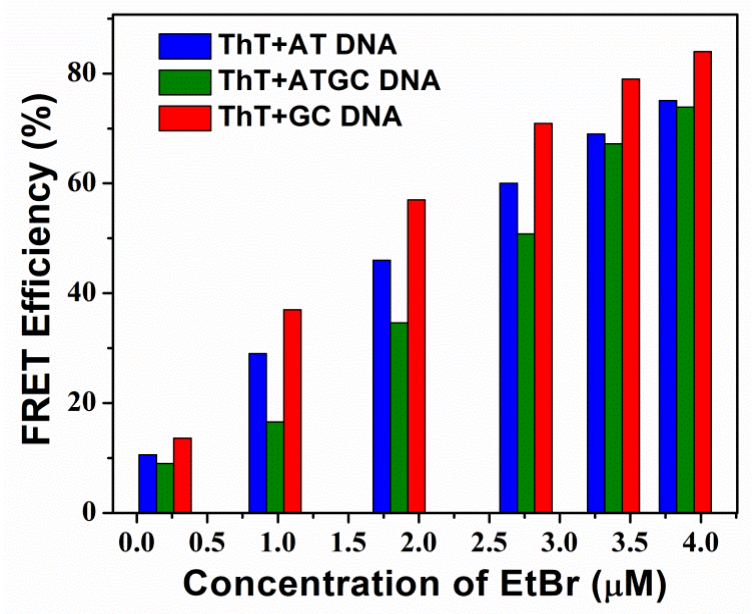

Figure S14. FRET efficiency plot of different DNA bound ThT 
Table S5. CIE Values of ThT-AT DNA in the Presence of EtBr. The CIE Coordinates (X=0.34 and Y=0.39) Representing the Emission of White Light are Marked in Bold Along with the Corresponding Concentration of EtBr.

\begin{tabular}{ccc}
\hline Concentration of $\operatorname{EtBr}(\mu \mathrm{M})$ & $\mathrm{X}$ & $\mathrm{Y}$ \\
\hline 0 & 0.15 & 0.38 \\
0.2 & 0.16 & 0.38 \\
0.98 & 0.19 & 0.38 \\
1.86 & 0.23 & .038 \\
2.76 & 0.27 & 0.39 \\
3.38 & 0.31 & 0.39 \\
$\mathbf{3 . 8 9}$ & $\mathbf{0 . 3 4}$ & $\mathbf{0 . 3 9}$ \\
4 & 0.38 & 0.40 \\
4.5 & 0.39 & 0.40 \\
\hline
\end{tabular}

Table S6. CIE CIE Values of ThT-ATGC DNA in the Presence of EtBr. The CIE Coordinates (X=0.34 and Y=0.39) Representing the Emission of White Light are Marked in Bold Along with the Corresponding Concentration of EtBr.

\begin{tabular}{ccc}
\hline Concentration of $\operatorname{EtBr}(\mu \mathrm{M})$ & $\mathrm{X}$ & $\mathrm{Y}$ \\
\hline 0 & 0.15 & 0.38 \\
0.2 & 0.17 & 0.38 \\
0.98 & 0.21 & 0.38 \\
1.86 & 0.26 & .038 \\
2.76 & 0.31 & 0.39 \\
$\mathbf{3 . 0 8}$ & $\mathbf{0 . 3 4}$ & $\mathbf{0 . 3 9}$ \\
3.38 & 0.36 & 0.40 \\
3.89 & 0.39 & 0.40 \\
\hline
\end{tabular}

Table S7. CIE Values of ThT-GC DNA in the Presence of EtBr. The CIE Coordinates (X=0.34 and Y=0.39) Representing the Emission of White Light are Marked in Bold Along with the Corresponding Concentration of EtBr.

\begin{tabular}{ccc}
\hline Concentration of $\operatorname{EtBr}(\mu \mathrm{M})$ & $\mathrm{X}$ & $\mathrm{Y}$ \\
\hline 0 & 0.16 & 0.38 \\
0.2 & 0.18 & 0.38 \\
0.98 & 0.25 & 0.38 \\
1.27 & 0.27 & .038 \\
1.57 & 0.30 & 0.39 \\
1.86 & 0.32 & 0.39 \\
$\mathbf{2 . 1 3}$ & $\mathbf{0 . 3 4}$ & $\mathbf{0 . 3 9}$ \\
2.38 & 0.36 & 0.39 \\
2.76 & 0.38 & 0.39 \\
3.38 & 0.42 & 0.39 \\
\hline
\end{tabular}




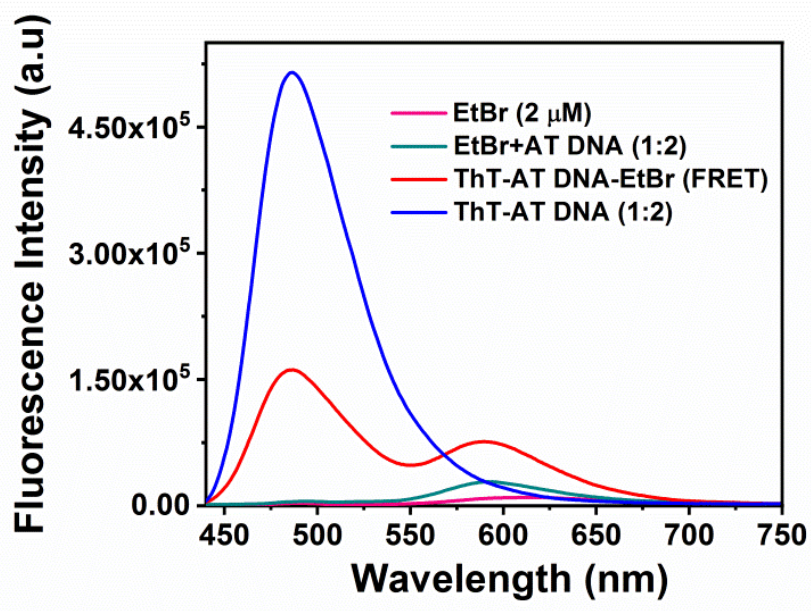

Figure S15. Comparison of the fluorescence spectra of bare EtBr, DNA bound EtBr, ThT-DNA and ThT-DNAEtBr FRET pairs at $420 \mathrm{~nm}$ excitation wavelength.
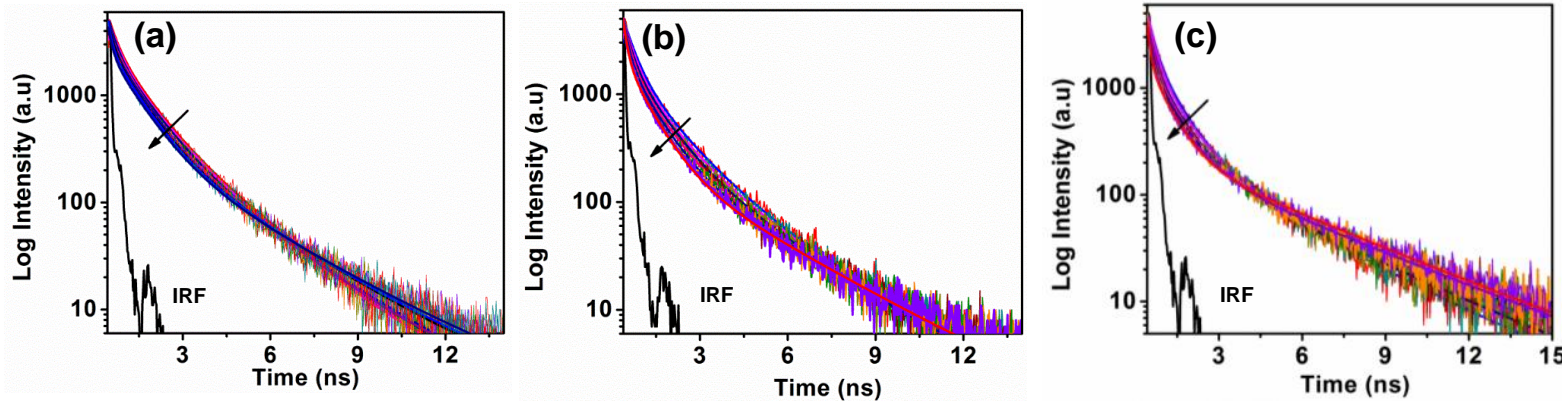

Figure S16. Fluorescence lifetime (in logarithm scale) of (a) ThT-AT-DNA, (b) ThT-ATGC DNA and (c) ThTGC DNA in the presence of different concentrations of EtBr. Data were recorded at emission wavelength of 486 $\mathrm{nm}$ wavelength under $405 \mathrm{~nm}$ excitation.

Table S8. Fluorescence lifetime data of ThT-AT DNA in the presence of EtBr

\begin{tabular}{ccccc}
\hline Concentration of EtBr & $\tau_{1} \mathrm{~ns}\left(\alpha_{1} \%\right)$ & $\tau_{2} \mathrm{~ns}\left(\alpha_{2} \%\right)$ & $\tau_{3} \mathrm{~ns}\left(\alpha_{3} \%\right)$ & $\chi^{2}$ \\
\hline 0 & $1.01(47.10)$ & $0.35(19.83)$ & $2.22(33.07)$ & 1.36 \\
$0.98 \mu \mathrm{M}$ & $0.97(49.10)$ & $0.29(17.17)$ & $2.19(33.73)$ & 1.39 \\
$1.86 \mu \mathrm{M}$ & $0.96(55.03)$ & $0.23(15.12)$ & $2.36(29.85)$ & 1.14 \\
$2.45 \mu \mathrm{M}$ & $0.91(54.58)$ & $0.22(13.83)$ & $2.33(31.59)$ & 1.15 \\
$2.76 \mu \mathrm{M}$ & $0.92(57.51)$ & $0.19(13.94)$ & $2.49(28.55)$ & 1.09 \\
$3.38 \mu \mathrm{M}$ & $0.85(51.97)$ & $0.18(13.6)$ & $2.31(34.43)$ & 1.3 \\
$3.89 \mu \mathrm{M}$ & $0.85(55.14)$ & $0.16(13.20)$ & $2.53(31.66)$ & 1.22 \\
$4.5 \mu \mathrm{M}$ & $0.85(57.02)$ & $0.13(10.30)$ & $2.61(32.68)$ & $2.83(31.89)$ \\
$4.65 \mu \mathrm{M}$ & $0.84(55.54)$ & $0.14(12.57)$ & & \\
\hline
\end{tabular}


Table S9. Fluorescence lifetime data of ThT-ATGC DNA in the presence of EtBr

\begin{tabular}{|c|c|c|c|c|}
\hline Concentration of $\mathrm{EtBr}$ & $\tau_{1} \mathrm{~ns}\left(\alpha_{1} \%\right)$ & $\tau_{2} \mathrm{~ns}\left(\alpha_{2} \%\right)$ & $\tau_{3} \mathrm{~ns}\left(\alpha_{3} \%\right)$ & $\chi^{2}$ \\
\hline 0 & $1.11(45.20)$ & $0.35(28.80)$ & $2.52(26.00)$ & 1.38 \\
\hline $0.98 \mu \mathrm{M}$ & $0.90(43.96)$ & $0.28(24.14)$ & $2.36(31.90)$ & 1.34 \\
\hline $0.86 \mu \mathrm{M}$ & $0.86(48.65)$ & $0.23(30.12)$ & $2.39(21.23)$ & 1.10 \\
\hline $2.45 \mu \mathrm{M}$ & $0.88(50.43)$ & $0.21(22.59)$ & $2.59(26.98)$ & 1.13 \\
\hline $2.76 \mu \mathrm{M}$ & $0.77(51.78)$ & $0.16(19.00)$ & $2.58(29.22)$ & 1.09 \\
\hline $3.38 \mu \mathrm{M}$ & $0.75(52.48)$ & $0.14(18.83)$ & $2.7428 .69)$ & 1.01 \\
\hline $3.89 \mu \mathrm{M}$ & $0.74(53.30)$ & $0.13(17.99)$ & $2.82(28.71)$ & 0.99 \\
\hline
\end{tabular}

Table S10. Fluorescence lifetime data of ThT-GC DNA in the presence of EtBr

\begin{tabular}{|c|c|c|c|c|}
\hline $\begin{array}{c}\text { Concentration of } \\
\mathrm{EtBr}\end{array}$ & $\tau_{1} \operatorname{ns}\left(\alpha_{1} \%\right)$ & $\tau_{2} \mathrm{~ns}\left(\alpha_{2} \%\right)$ & $\tau_{3} \mathrm{~ns}\left(\alpha_{3} \%\right)$ & $\chi^{2}$ \\
\hline 0 & 0.99 (45.72) & $0.30(31.61)$ & $3.43(22.67)$ & 1.17 \\
\hline $0.98 \mu \mathrm{M}$ & $0.92(43.66)$ & $0.26(26.37)$ & 3.37 (29.97) & 1.15 \\
\hline $1.86 \mu \mathrm{M}$ & $0.85(48.29)$ & $0.22(21.65)$ & 3.58 (30.06) & 1.08 \\
\hline $2.45 \mu \mathrm{M}$ & $0.84(45.21)$ & $0.19(22.34)$ & $3.75(32.45)$ & 1.15 \\
\hline $2.76 \mu \mathrm{M}$ & $0.80(44.99)$ & $0.16(18.94)$ & 3.85 (36.07) & 1.11 \\
\hline $3.38 \mu \mathrm{M}$ & 0.78 (44.92) & $0.16(17.25)$ & $3.87(37.83)$ & 1.16 \\
\hline $3.89 \mu \mathrm{M}$ & $0.69(40.64)$ & $0.11(22.05)$ & $4.01(37.31)$ & 1.27 \\
\hline
\end{tabular}

\section{References.}

S1. Das, N. K.; Ghosh, S.; Priya, A.; Datta, S.; Mukherjee, S. Luminescent Copper Nanoclusters as a Specific Cell-Imaging Probe and a Selective Metal Ion Sensor. J. Phys. Chem. C 2015, 119, 24657-24664.

S2. Nandy, A.; Chakraborty, S.; Nandi, S.; Bhattacharyya, K.; Mukherjee, S. Structure, Activity, and Dynamics of Human Serum Albumin in a Crowded Pluronic F127 Hydrogel. J. Phys. Chem. B 2019, 123, 3397-3408.

S3. Chakraborty, S.; Nandi, S.; Bhattacharyya, K.; Mukherjee, S. Probing Viscosity of Co-polymer Hydrogel and HeLa Cell by Fluorescent Gold Nanoclusters: Fluorescence Correlation Spectroscopy and Anisotropy Decay. ChemPhysChem 2020, 21, 406-414.

S4. Das, D. K.; Mondal, T.; Mandal, A. K.; Bhattacharyya. K. Binding of Organic Dyes with Human Serum Albumin: A Single-Molecule Study. Chem. Asian J. 2011, 6, 3097-3103. 
S5. Morris G. M.; Goodsell D. S.; Halliday R. S.; Huey R.; Hart W. E.; Belew R. K.; Olson A. J. Automated Docking Using a Lamarckian Genetic Algorithm and an Empirical binding Free Energy Function. J. Comput. Chem. 1998, 19, 1639-1662.

S6. Krishna P. M.; Reddy N. B. G.; B. G. Yogesh H.; Patil P.; Nethaji M. Synthesis, Structural Studies, Molecular Docking and DNA Binding Studies of 4N-substituted Hydrazinecarbothioamides. J. Mol. Struc. 2019, 1175, 97-104.

S7. Frisch M. J.; Trucks G. W.; Schlegel H. B.; Scuseria G. E.; Robb M. A.; Cheeseman J. R.; Scalmani G., Barone V.; Mennucci B.; Petersson G. A.; et al., Gaussian 09 Revision E. 01, Inc., Pittsburg, PA, 2009.

S8. Hanwell M. D.; Curtis D. E.; Lonie D. C.; Vandermeersch T.; Zurek E.; G. Hutchison R. Avogadro: An Advanced Semantic Chemical Editor, Visualization, and Analysis Platform. $J$. Cheminform. 2012, 4, 1-17.

S9. Schrödinger, LLC, The PyMOL Molecular Graphics System, Version 1.8, 2015. 